\title{
Underground Construction Impact the Ground Water Resources: A Review
}

\author{
Sumant Kumar Verma \\ Department of Civil Engineering, Buddha Institute of Technology, Gorakhpur, India
}

Email address:

sumant454@bit.ac.in

\section{To cite this article:}

Sumant Kumar Verma. Underground Construction Impact the Ground Water Resources: A Review. Landscape Architecture and Regional Planning. Vol. 3, No. 2, 2018, pp. 23-27. doi: 10.11648/j.larp.20180302.11

Received: April 4, 2018; Accepted: April 28, 2018; Published: May 25, 2018

\begin{abstract}
An ancient time most of the famous and developed historical cities grow near bank of river. Because availability of fresh water for their fulfilment of water requirement. River water was only source of fresh water resource. Due to globalization, modernization and industrialization increase the demand or requirement of water for their activities and further increase pollution of Surface water and Ground water. Today most of the water bodies (surface and ground water sources) have polluted commercial and industrial growth. The rapid development of cities and industries causes a over utilization of land. Due to this congestion population moves on underground structure. This article point out regarding impact of tunneling on subsurface construction (deep foundation, tunnel, basement etc.) on degradation of underground water resources and also obstruct the movement of water on aquifer. The underground construction done in the subsurface levels of urban areas are represents and consolidated in terms of their influence on sub surface water and prevented to the movement or damage the groundwater budget of the flow system.
\end{abstract}

Keywords: Groundwater Flow, Underground Constructions, Tunneling, Dewatering, Ground Water Depletion

\section{Introduction}

Water is a naturally available most important water resource and it is vital for all kinds of life in world. Water resource is sometime abundant and sometime scare; it is unevenly distributed over the earth. Water resource is categories in different forms on the earth such as surface water, ground water, and atmospheric water.

Sometime the earth is called blue planet, because ocean cover $71 \%$ of the earth surface and it is appear blue from the space. In the earth total amount of water available is estimated about 1.4 billion cubic kilometer, which is cover up to $3 \mathrm{Km}$ deep in earth. About $97.2 \%$ (1.33 million cubic Kilometer) of saline water present in oceans and 2.1\% (29.3 million cubic Kilometer) water is frozen in polar ice-caps. Total saline water is $99.31 \%$ which is no used to human. And remaining about $0.61 \%$ (8.45 million cubic kilometer including ground water, lakes, rivers and soil moisture) of available water is fresh water.

The geographical area of India is world $2.4 \%(3150 \mathrm{Km})$ of areas is cover. Total annual precipitation (including snow fall) in India is about 4000 cubic Kilometer and average annual precipitation is about $1105 \mathrm{~mm}$ in average rainy days
5 to 150 days. In addition to average annual potential flow in rivers is estimated about 1850 cubic Kilometer and utilizable water resources is accounted about 1120 cubic Kilometer, it is contains surface water and replenish able ground water about 690 and 430 cubic Kilometer.

As we know that about only $2 \%$ ground water found in subsurface level and rest about 70 to $80 \%$ water exist in ocean, glaciers, river, lakes etc mostly not used for drinking purpose. Due to continuous apathy of over exploitation of subsurface water most of the countries suffering from scarcity of water problem.

Groundwater is something that we need all over the world. Humans and animals need water in order to survive as our bodies could not function without it. We also need water to assist us in growing crops, powering equipment, and to keep us comfortable. Societies require much more clean water than we are afforded from precipitation and surface water, which is why groundwater is used so frequently.

This paper contains lot of information related to degradation of subsurface water which published in government, state government, local body and news articles. Every time published article related this issues in different news papers and magazines. in this paper we tried to collect 
as much information as we found from already published article.

\section{Literature Review}

Half of the world's population now lives in cities. The phenomenon of urbanisation is such that this proportion will reach $70 \%$ (Un-Habitat, 2008) by 2050. Despite this anticipated anthropic pressure, the protection of natural spaces remains a major challenge in the effort to limit horizontal urban sprawl. The influence of the two main constraints, anthropic pressure and property economics, leads (mechanically) to the vertical development of urban areas, particularly due to the potential provided by some subsoils to support urban growth. In particular, the resilience of groundwater resources appears to be a major issue. Although $40 \%$ of the water distributed in the water supply networks of Europe comes from urban aquifers (Eiswirth et al., 2004), urban densification is leading to the construction of everdeeper structures (Bobylev, 2009): subways, building foundations, underground carparks, etc., that interact with this resource. Several reviews in the literature have focused on the qualitative and quantitative pressures affecting urban aquifers. The review by Lerner (2002) presents the specific characteristics of urban groundwater recharge linked to artificial drainage networks, buildings and transport infrastructures. It also presents an account of the extent of anthropic contributions, in the form of leaks from underground pipes, to recharging urban aquifers.

The review by Rutsch et al. (2008) focuses on the different methods used to identify and quantify leaks from drainage networks. They present the analytical solutions describing this phenomenon. The review by Schirmer et al. (2013) focuses on the factor of complexity of urban hydrogeology, such as the heterogeneity of land-use and the presence of underground networks which lead to spatial and temporal variations in flows of water and contaminants.

Contrary to the qualitative and quantitative influences of water supply and drainage networks on groundwater, which have been the subjects of several studies, the role played by other underground structures such as tunnels and the foundations of large buildings is often excluded from urban hydrogeology studies and these aspects are not covered by previous review papers. The interaction between groundwater and these structures can present risks and generate disturbances. Water drainage associated with underground structures can impact groundwater quality (Chae et al. 2008), and drainage generates piezometric depressions giving rise to areas of compaction (NSREA, 1995; Yoo et al. 2009; Modoni et al. 2013). On the other hand, damage to buildings can be caused by the rise in groundwater levels resulting in flooding of lower building levels, excessive hydrostatic stress exerted on buildings, and the corrosion of foundations (Lerner and Barrett 1996). In addition, the heat island effect on groundwater due to urbanization is well observed for many cities around the world (Zhu et al. 2010; Taniguchi et al. 2009, Menberg et al.
2013). Geothermal heat can be regarded as a strategic urban resource (Lund et al. 2011; Herbert et al. 2013); since underground structures can significantly affect groundwater temperatures (Epting et al. 2013), this impact of urbanisation can be important. According to Benz et al. 2015, buildings reaching into or close to the groundwater generate a major part of the total anthropogenic heat flux received by groundwater.

According to Zhang et al. (2011) the lack of expertise and understanding of the interactions between different underground structures and groundwater remain an obstacle to the improvement of three-dimensional urban planning. In particular, understanding groundwater flow in an urban context is the first step to improve qualitative and quantitative groundwater resource management. As a consequence, this review covers articles dealing with the quantitative impacts and interactions of underground structures (e.g. deep foundations, tunnels, underground car parks) on groundwater flow, in an urban context. In this paper, the impact on groundwater flow is considered as a modification of the flow system, or an evolution of watertable elevation, or a disturbance of groundwater budget, induced by an underground structure. Groundwater quality issues related to underground structures (e.g. sewer leakages and contamination) are not covered by this review.

\subsection{Delhi Ground Water Resource Highly Depleted due to DMRC Project}

A report on website of one India has published that after analysing Delhi's groundwater table data in past one decade the board has concluded that the national capital's overall groundwater level is depleting by a maximum of 1.44 metres per year because of increased extraction. As per a Hindustan Times report, the board on September 1 had asked the DMRC to get a detailed groundwater impact study done through a reputed consultant and submit a report with details on quality and quantity of water being drawn, site-wise utilization, impact on water table and recharge plans.

"Heavy de-watering is going to impact groundwater situation adversely. Delhi is notified for falling water table. DMRC should have undertaken comprehensive impact studies as well as prior clearance before starting dewatering," the letter said. The board in its report has further said that the metro has neither taken enough measures to conserve groundwater nor has it done a proper study of water disposal plans. CGWB has also accused the DMRC of not taking proper permission from the Delhi Jal Board (DJB) before extracting water. Earlier last year, National Green Tribunal (NGT) had served notice to the DMRC for failing to harvest rainwater at its stations and depots.

\subsection{Delhi Groundwater Reserves Depleting at Alarming Rate Finds CGB Study}

A report on website of India Today has published that Delhi will have to increasingly depend on its reluctant neighbours to meet the water demand of its burgeoning 
population as its groundwater reserves are depleting fast.

A latest Central Groundwater Board (CGB) study across the country has painted a rather depressing picture on the availability of groundwater in Delhi.

The study, which was put on its website recently following an extensive compilation of data for close to two years, divided Delhi into 27 tehsils and termed the groundwater situation in five of them "semi-critical", and 20 "over-exploited".

In fact, with the exceptions of north and north-east Delhi, all other seven districts fall in the "over-exploited" zone with south Delhi faring the worst. Things are almost equally bad in east Delhi, whose net groundwater usage was 2,208 HAM against the recharge of 1,284 HAM.

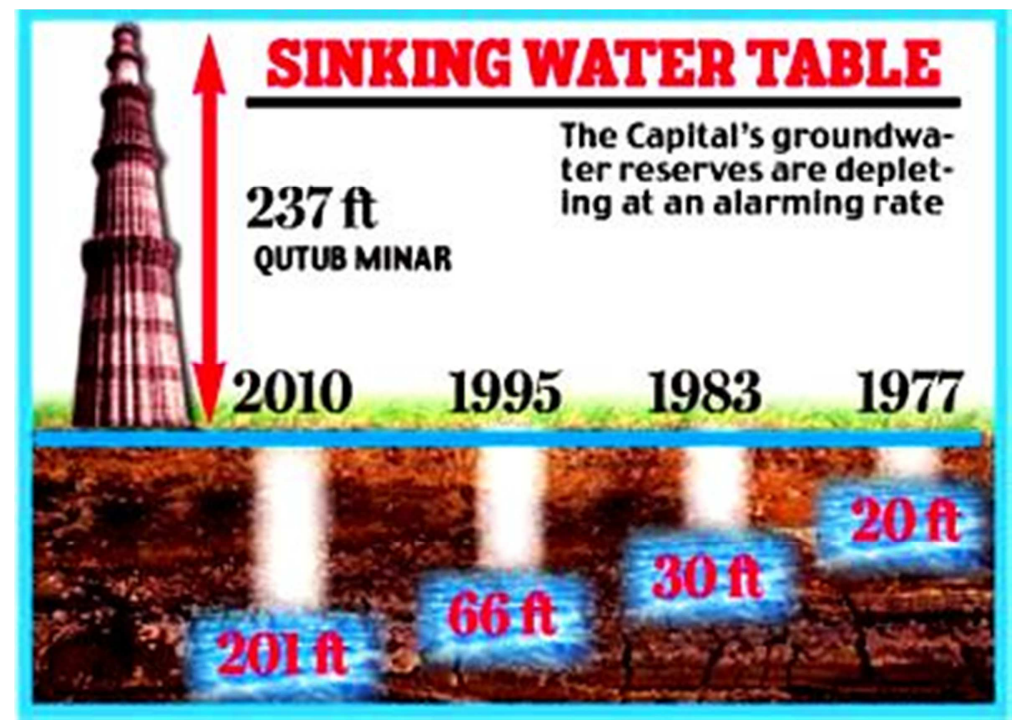

Figure 1. Comparative image of Sinking Water Table.

\section{Modern Tunneling Operation}

\subsection{Establish TBM to Suitable Place}

In this, first shaft is made to the ground where TBM have to install. Than after TBM is installed at proper site under the ground with the help of ultra modern instruments and man power.

\subsection{Cutting and Soil Removal Operations of TBM}

Install TBM at place where tunneling operation is start. After placing TBM at tunneling location starts cutting of soil by sharp cutter and blades.

\subsection{Forward Straight Drilling Operations}

For the horizontal tunneling operation a mechanical arrangement provide with TBM i.e. Jack. Jack help to guide the TBM for horizontal drilling operation with faster rate.

\subsection{Lining Operations}

Lining or straighten operation is done mechanically with the help of various automate robotic systems. This lining provides support to the tunnel walls and prevent sliding and dangerous accidents.

\subsection{Finishing Works/Operations}

Finishing work, electrification, ventilation, and concreting etc. work proceed after completion of drilling operation.

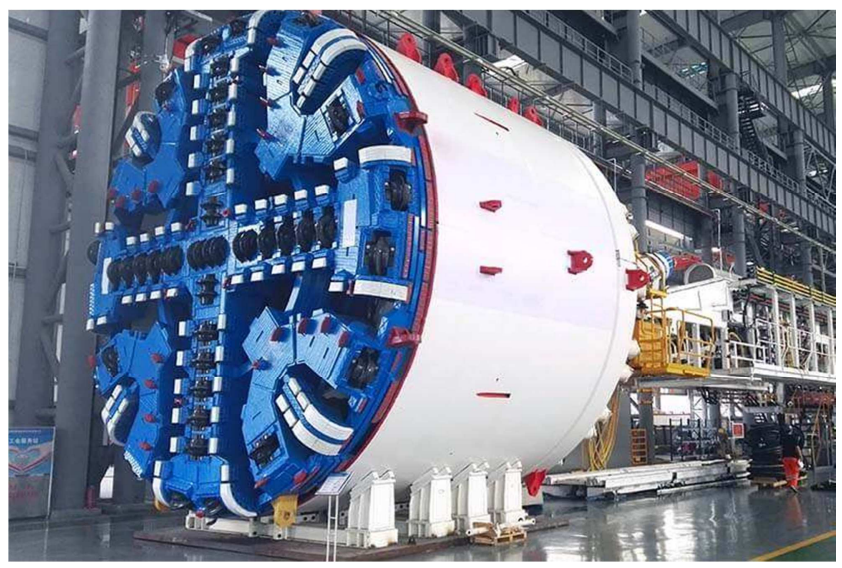

Figure 2. Tunnel Boring Machine.

\section{Dewatering for Tunneling}

Dewatering and groundwater control is often required as part of tunneling projects - dealing with groundwater is one of the challenges of working underground.

The whole purpose of dewatering on tunnel projects is to permit excavation, lining or straighten and other construction works to be done with safety in dry and stable conditions. The most general tunneling situations where groundwater control techniques are needed include:

Pumped well systems, electric power, man power and low permeability cut-off walls or a combination of these techniques are required for tunnelling operation to construct shafts or station boxes to launch or receive Tunnel Boring 


\section{Machines}

After tunneling operation most of of structure are temporarily exposed like cross passages, tunnel enlargement, adits or other connections. This can be achieving by pumped well systems, guniting, grouting, artificial ground freezing or a combination of these techniques.
Sometime during the tunneling operation all major and minor equipments are gets damaged by flooding. Pumped well dewatering to lower groundwater levels to below invert to allow open face tunnelling methods to be used in otherwise unstable ground.

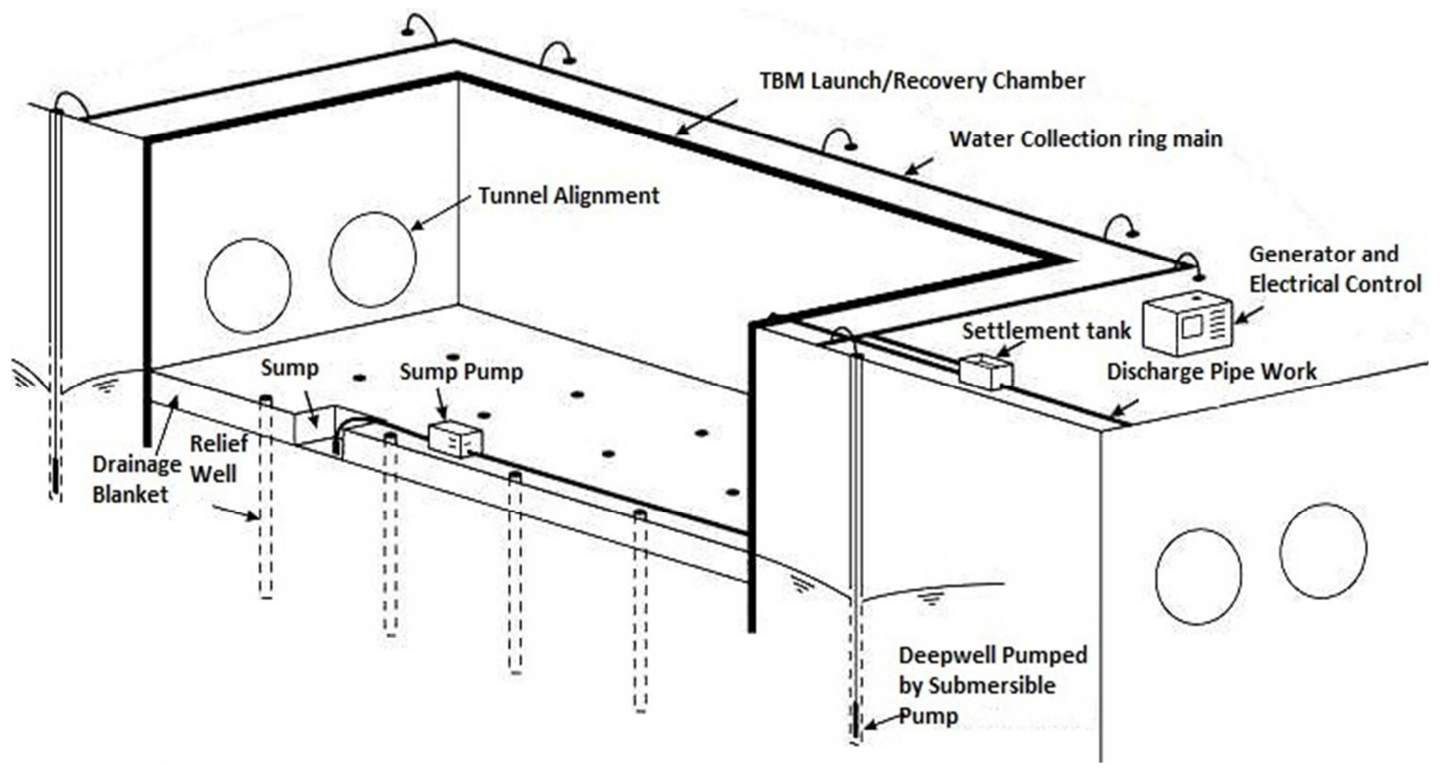

Figure 3. Extraction of water from aquifer.

\section{Metro Projects in India}

India plans to develop Metro Rail projects in over 30 Indian cities. Currently, the metro rail network is operational or partly operational in nine cities and another five cities have under-implementation metro projects (Rachita Prasad 2017).

Table 1. Some list of Metro projects in India.

\begin{tabular}{llll}
\hline Sn. & Metro Projects & $\begin{array}{l}\text { Ground water table } \\
(\mathbf{1 9 9 2 - 1 9 9 5 )} \text { in feet }\end{array}$ & $\begin{array}{l}\text { Ground water table } \\
(\mathbf{2 0 1 0 - 2 0 1 4 )} \text { in feet }\end{array}$ \\
\hline 1 & Delhi Metro & 66 & 201 \\
2 & Jaipur & 94.73 & 155.80 \\
3 & Gurgaon & 98.42 & 137.7 \\
4 & Chennai & 75.4 & 142 \\
\hline
\end{tabular}

Source: all data collected from different news reports and government published reports.

\section{Conclusion}

Urban underground is a complex system with many operating man-made infrastructures (e.g. underground buildings, subway lines, sewer networks, heat pump schemes). These structures disturb the natural flow and quality of groundwater. The literature shows that lots of studies deal with the individual impacts of underground structures on groundwater flow. Regarding the structure area, several approaches developed sensitivity analysis or analytical solutions to quantify the barrier effect of impervious structures, and the interaction (i.e. infiltration or exfiltration rate) between sewer and water supply networks.

According to the authors of this review, the chain-reaction generated by the modification of urban groundwater flow on groundwater quality and quantity have to be considered. The first step for a better knowledge in the qualitative and the quantitative influence of underground structures on groundwater should be to focus on the flow in urban areas. Several recommendations are proposed for future research in urban hydrogeology regarding the improvement of urban underground planning.

\section{References}

[1] Guillaume Attard, Thierry Winiarski, Yvan Rossier, Laurent Eisenlohr "Review: Impact of underground structures on the flow of urban groundwater" Hydrogeology Journal, February 2016, Volume 24, Issue 1, pp 5-19, 2016.

[2] Attard G, Winairski T, Rossier Y, Eisenlohr L "Urban Underground Space Management: An Approach by Indicators for Groundwater Protection". In: Lollino G, Arattano M, Rinaldi M, Giustolisi O, Marechal J-C, Grant GE (eds.) Engineering Geology for Society and Territory - Volume 3. Springer International Publishing, 2015.

[3] Bobylev N Mainstreaming sustainable development into a city's Master plan: A case of Urban Underground Space use. Land Use Policy, 26, 1128-1137, 2009

[4] Bonomi T, Bellini R "The tunnel impact on the groundwater level in an urban area": a modelling approach to forecast it. Materials and Geoenvironment, 50, 45-48, 2003. 
[5] Boreux V, Born J, Lawes MJ "Sharing Ecological Knowledge: Opportunities and Barriers to Uptake". Biotropica, 41, 532534, 2009.

[6] Boukhemacha A MA, Gogu CR, Serpescu I, Gaitanaru D, Bica, "A hydrogeological conceptual approach to study urban groundwater flow in Bucharest city, Romania. Hydrogeology" Journal, 1-14, 2015.

[7] Butscher C Steady-state groundwater inflow into a circular tunnel. Tunnelling and Underground Space Technology, 32, 158-167, 2012.
[8] Cedergren HR Seepage, drainage, and flow nets, John Wiley \& Sons, 1997.

[9] Epting J, Huggenberger P "Unraveling the heat island effect observed in urban groundwater bodies" - Definition of a potential natural state. Journal of hydrology, 501, 193-204. doi:10.1016/j. jhydrol.2013.08.002, 2013.

[10] Benz SA, Bayer P, Menberg K, Jung S, Blum P "Spatial resolution of anthropogenic heat fluxes into urban aquifers". Science of The Total Environment, 524-525, 427-439, doi:10.1016/j. scitotenv.2015.04.003, 2015. 